\title{
Interleukins and neurohormones: a common language
}

\author{
Richard Knight, Nicholas Sarlis ${ }^{1}$ and Anastasis Stephanou ${ }^{1}$
}

\author{
Department of Cystic Fibrosis, National Heart and Lung Institute, Manresa Road, London SW3 6LR, and \\ ${ }^{1}$ Neuroendocrine Unit, Charing Cross Hospital, London W6 8RF, UK
}

A characteristic of multicellular organisms is that groups of cells specialize as functional units. One example is the classical endocrine system, where central influences affect the release of releasing hormones, such as corticotrophin releasing hormone $(\mathrm{CRH})$ and growth hormone releasing hormone (GRH) from hypothalamic nuclei. These pass through the hypothalamic-hypophyseal portal circulation to the anterior pituitary and modulate release of the appropriate trophic hormones, such as adrenocorticotrophic hormone $(\mathrm{ACTH})$ and growth hormone (GH). The anterior pituitary hormones enter the systemic circulation, from where they are mostly delivered to endocrine end organs, such as the adrenal cortex, and there affect the release of the final hormone in the cascade.

For the multicellular organism to function in a coordinated way, however, the activities of these functionally specialized units need to be integrated. It is becoming clear that this integration is achieved, at least between some organ systems, by their sharing common chemical messages and receptors. Thus, any one system uses a set of chemicals both for communication between the cells of that system, and for integrative interactions with cells of a functionally distinct unit. Nowhere is this integrative interaction better illustrated than in the dialogue between the endocrine and immune systems.

Circumstantial associations between personality traits and 'stress' with disease susceptibility have been noted for several centuries. The effects of hypophysectomy ${ }^{1}$ and experimental electrolytic lesions in the hypothalamus ${ }^{2}$ on immune function, and the actions of classical endocrine hormones on immune responses in vitro ${ }^{3}$ provide more direct evidence for an endocrine-immune interaction. In the reverse direction, early experiments showed that hypophysectomized animals, which therefore lacked a pituitary source of ACTH, could still mount a steroidogenic response to stress. ${ }^{4}$ More

Correspondence: R.A. Knight, M.B., B.S., Ph.D.

Received: 9 April 1992

This article is based on a lecture given to the European Medical Research Group on 4 February 1992. recently, immune-derived interleukins (IL) have been shown to have direct endocrine effects. Thus IL1 causes release of corticosteroids from adrenal cells, ${ }^{5}$ and IL1, 2 and 6 all have effects on pituitary production of ACTH. ${ }^{6-8}$ Indeed, some ILs have been shown to be present in the pituitary gland itself. $^{9}$

The effects of endocrine hormones on immune responses in vitro have been particularly well studied. Both hypothalamic releasing hormones $(\mathrm{CRH}, \mathrm{GRH})^{10}$ and anterior pituitary peptides (prolactin, $\mathrm{GH}$, thyroid stimulating hormone, ACTH and $\beta$ endorphin $)^{11-13}$ have some activity.T cell proliferation, natural killing (NK), antibody production and neutrophil function may all be affected. The actions of $\beta$ endorphin on NK and antibody production are particularly interesting. Biphasic effects are seen on both types of immune reaction, with the production of specific antibodies to Herpes simplex virus being enhanced in vitro at concentrations as low as $10^{-18} \mathrm{~mol} / 1 .{ }^{14} \mathrm{We}$ have also observed effects of CRH on NK down to $10^{-18} \mathrm{~mol} / 1$ (unpublished observations).

The low molarities at which these immunomodulatory effects are seen - considerably lower than the circulating plasma concentrations - suggests that inflammatory cells themselves produce neurohormones which act very locally on neighbouring cells within an inflammatory focus or lymph node. There is now good evidence, both at the level of gene transcription and of peptide production, that this is indeed the case. For example, both lymphocytes and neutrophils contain mRNA transcripts of the proopiomelanocortin (POMC) gene - the precursor to ACTH and $\beta$ endorphin. ${ }^{15}$ Moreover, ACTH and $\beta$ endorphin peptides have been detected in supernatants of activated lymphocytes. ${ }^{16}$ The accumulation of POMC transcripts increases with lymphocyte activation.

Recently, we have also detected mRNAs and peptides related to CRH and GRH in human lymphocytes, ${ }^{17,18}$ although there is approximately 10 times as much GRH as CRH. Although the peptides contained within resting lymphocytes, and released into supernatants after cell activation, react with the appropriate antisera, they behave 
differently biochemically. However, the lymphocyte-derived CRH and GRH are able to induce transcription of POMC and GH genes, respectively, in both lymphocytes and pituitary cells, and therefore have appropriate biological activities. It has also been reported in the mouse that lymphocyte-derived ACTH is a truncated form of the pituitary peptide. ${ }^{19}$ These biochemical differences between the lymphocyte-derived peptides and their hypothalamic and pituitary equivalents may allow the discrimination of the relative roles of lymphocyte and hypothalamic/ pituitary peptides in immunomodulation.

However, much still remains to be understood in this new field of neuroimmunology. It is unknown, for example, whether all inflammatory cells can produce all neurohormones, or whether distinct subsets produce only a limited and characteristic profile. If the latter proves correct, does this lead to a new functional classification of inflammatory cells, similar to the discrimination of Th1 and Th2 subsets of helper $\mathrm{T}$ lymphocytes in the mouse on the basis of their production of IL2 or IL4 respectively? ${ }^{20}$ Again, no systematic studies on the interrelationship of ILs and interferons with inflammatory neurohormones have been reported, although exogenous IL2 does increase lymphocyte expression of POMC. ${ }^{15}$ Equally importantly, are the concentrations of inflammatory neurohormonal peptides sufficient only for very local interactions with neighbouring inflammatory cells, can they affect parenchymal cells of the organ in which the inflammation is taking place, or can they even exert systemic effects?

It is possible, however, to consider the potential pathogenic importance of inflammatory neurohormones. The expression of GRH and GH by lymphocytes has been discussed above. The final mediator of most of the peripheral actions of $\mathrm{GH}$ is insulin-like growth factor 1 (IGF1). It has recently been shown that alveolar macrophages (AM) and lymphocytes can themselves make IGF1, ${ }^{21,22}$ and that AM express IGF 1 receptors. ${ }^{23}$ IGF 1 increases superoxide production by both neutrophils and AM. ${ }^{24}$ Since the activated neutrophils and AM in the chronically infected lungs of patients with bronchiectasis or cystic fibrosis will already be producing free radicals, which cause tissue damage, any enhancement of free radical production by inflammatory cell-derived IGF 1 could be still more disadvantageous. IGF1 is also fibrogenic. It causes

\section{References}

1. Nagy, E. \& Berczi, I. Immunodeficiency in hypophysectomised rats. Acta Endocrinol 1978, 89: 530-537.

2. Forni, G., Bindoni, M., Santoni, A., Belluardo, N., Marchese, A.E. \& Giovarelli, M. Radiofrequency destruction of the tuberoinfundibular region of hypothalamus permanently abrogates NK cell activity in mice. Nature 1984, 306: $181-184$ fibroblast proliferation and collagen deposition. ${ }^{25}$ Moreover, mice bearing a chronically expressed GH transgene, and who have high circulating levels of IGF1, develop a glomerulosclerosis with increased transcription of collagen, laminin and heparan sulphate proteoglycan genes. ${ }^{26}$ It would, therefore, be appropriate to assess the contribution of inflammatory GFH-GH-IGF1 to the fibrosis common in chronic inflammatory disease, particularly as agents are already available which can inhibit this pathway.

A further example is the interaction of tumours with tumour infiltrating inflammatory cells. We have been particularly interested in tumours of neuroectodermal origin, since it is some of these in which the best documented cases of immunologically mediated regression have been reported. ${ }^{27}$ Neuroblastomas, for example, elaborate a wide range of neurohormones, some of which, like IGF2 and $\boldsymbol{\beta}$ endorphin have been proposed as autonomous growth-promoting factors for the tumours themselves. ${ }^{28,29}$ POMC expression in neuroblastoma is reduced when the cells are induced to differentiate in vitro by agents such as retinoic acid, and opiate antagonists modulate the growth of neuroblastoma cells both in vivo and in vitro. ${ }^{30}$ Evidence is also accumulating that neuroectodermal tumours produce some interleukins and IL 1 expression in melanoma has been correlated with its metastatic potential. ${ }^{31}$ Thus, the production of common peptides - both neurohormones and interleukins - by tumours and the inflammatory cells that infiltrate them suggests that tumours may influence the nature of their local inflammation in the same way as the inflammatory cells affect the growth, differentiation and metastasis of the tumour. Clearly, a better understanding of these interactions has considerable therapeutic potential.

Therefore, at least some organ systems and tumour cells share a common chemical language. The individual chemical terms may have different meanings depending on whether they are being used as communication elements within or between systems. Moreover, the physiological and pathological meaning of a particular chemical word may depend on the chemical syntax within which it is being expressed. Learning how to interpret and manipulate this language holds exciting possibilities for future medical practice.

3. Smith, E.M. \& Blalock, J.E. A molecular basis for interactions between the immune and neuroendocrine systems. Int $J$ Neurosci 1988, 38: 455-467.

4. Smith, E.M., Meyer, W.J. \& Blalock, J.E. Virus-induced corticosterone in hypophysectomised mice: a possible lymphoid-adrenal axis. Science 1982, 218: 1311-1313. 
5. Winter, J.S.D., Gow, K.W., Perry, Y.S. \& Greenberg, A.H. A stimulatory effect of interleukin-1 on adrenocortical cortisol secretion mediated by prostaglandins. Endocrinology 1990, 127: $1904-1909$.

6. Uehara, A., Gottschall, P.E., Dahl, R.P. \& Arimura, A. Interleukin 1 stimulates ACTH release by an indirect action which requires endogenous corticotropin-releasing factor. Endocrinology 1987, 121: 1580-1582.

7. Brown, S.L., Smith, L.R. \& Blalock, J.E. Interleukin 1 and Interleukin 2 enhance proopiomelanocortin gene expression in pituitary cells. $J$ Immunol 1987, 139: 3181-3183.

8. Naitoh, Y., Fukata, J., Tominaga, T. et al. Interleukin-6 stimulates the secretion of adrenocorticotropic hormone in conscious freely moving rats. Biochem Biophys Res Comm 1988, 155: 1459-1462.

9. Koenig, J.J., Snow, W., Clark, B.D. et al. Intrinsic pituitary interleukin $1 \beta$ is induced by bacterial lipopolysaccharide. Endocrinology 1990, 126: 3053-3058.

10. Pawlikowski, M., Zelazowski, P., Doher, K.D. \& Stepien, H. Effects of two neuropeptides; somatoliberin (GHRH) and corticoliberin (CRF) on human lymphocytes natural killer activity. Brain Behav Immun 1988, 2: 50-56.

11. Chen, H.W., Meier, H., Heiniger, H.J. \& Huebner, R.J. Tumorigenesis in strain DW-J mice and induction by prolactin of the group-specific antigen of endogenous C-type RNA tumour virus. J Nat Cancer Inst 1972, 49: 1145-1153.

12. Snow, E.C., Feldbush, T.L. \& Oaks, J.A. The effect of growth hormone and insulin upon MLC responses and the generation of cytotoxic lymphocytes. J Immunol 1981, 126: 161 .

13. Johnson, H.M., Smith, E.M., Torres, B.A. \& Blalock, J.E. Regulation of the in vitro antibody response by neuroendocrine hormones. Proc Nat Acad Sci 1982, 79: 4171-4174.

14. Williamson, S.A., Knight, R.A., Lightman, S.L. \& Hobbs, J.R. Effects of beta-endorphin on specific immune responses in man. Immunology 1988, 65: 47-52.

15. Stephanou, A., Fitzharris, P., Knight, R.A. \& Lightman, S.L. Characteristics and kinetics of proopiomelanocortin mRNA expression by human leucocytes. Brain Behav Immun 1991, 5: 319-327.

16. Smith, E.M., Morrill, A.C., Meyer, W.J., III \& Blalock, J.E. Corticotrophin-releasing factor induction of leucocytederived immunoreactive ACTH and endorphins. Nature 1986, 321: 881-882.

17. Stephanou, A., Jessop, D.S., Knight, R.A. \& Lightman, S.L. Corticotrophin-releasing factor-like immunoreactivity and mRNA in human leucocytes. Brain Behav Immun 1990, 4: 67-72.

18. Stephanou, A., Knight, R.A. \& Lightman, S.L. Production of a growth hormone-releasing hormone-like peptide and its mRNA by human lymphocytes. Neuroendocrinology 1991, 53: $628-633$.
19. Smith, E.M., Galin, F.S., LeBoeuf, R.D., Coppenhaver, D.H., Harbour, D.V. \& Blalock, J.E. Nucleotide and amino acid sequence of lymphocyte-derived corticotropin: endotoxin induction of a trucated peptide. Proc Nat Acad Sci 1990, 87: 1057-1060.

20. Fernandez-Botran, R., Sanders, V.M., Mosmann, T.R. \& Vitettea, E.S. Lymphokine-mediated regulation of the proliferative response of clones of $T$ helper 1 and $T$ helper 2 cells. $J$ Exp Med 1988, 168: 543-558.

21. Rom, W.N., Basset, P., Fells, G.A., Nukiwa, T., Trapnell, B.C. \& Crystal, R.G. Alveolar macrophages release an insulin-like growth factor I-type molecule. J Clin Invest 1988, 82: $1685-1693$.

22. Baxter, J.B., Blalock, J.E. \& Weigent, D.A. Characterisation of immunoreactive insulin-like growth factor-I from leucocytes and its regulation by growth hormone. Endocrinology 1991, 129: 1727-1734.

23. Rom, W.N. \& Paakko, P. Activated alveolar macrophages express the insulin-like growth factor-1 receptor. Am Rev Respir Cell Mol Biol 1991, 4: 432-439.

24. Fu, Y.-K., Arkins, S., Wang, B.S. \& Kelley, K.W. A novel role of growth hormone and insulin-like growth factor I. Priming neutrophils for superoxide anion secretion. $J$ Immunol 1991, 146: 1602-1608.

25. Morrell, B. \& Froesh, E.R. Fibroblasts as an experimental tool in metabolic and hormone studies. II. Effects of insulin and nonsuppressible insulin-like activity (NSILA-s) on fibroblasts in culture. Eur J Clin Invest 1973, 3: 119-123.

26. Doi, T., Striker, L.J. \& Kimata, K. Glomerulosclerosis in mice transgenic for growth hormone. Increased mesangial extracellular matrix is correlated with kidney mRNA levels. $J$ Exp Med 1991, 173: 1287-1290.

27. Eklof, O., Sandstedt, B., Thonell, S. \& Ahstrom, L. Spontaneous regression of Stage IV neuroblastoma. Acta Paediatr Scand 1983, 72: 473-476.

28. El-Badry, O.M., Romanus, J.A., Helman, L.J., Cooper, M.J., Rechler, M.M. \& Israel, M.A. Autonomous growth of a human neuroblastoma cell line is mediated by insulin-like growth factor II. $J$ Clin Invest 1989, 84: 829-839.

29. Knight, R.A., Stephanou, A., Lightman, S.L. \& Williamson, S.A. CRF and POMC production by neuroectodermal tumours and lymphocytes, and its immunological consequences. Clin Chem Enzym Comm 1990, 2: 269-272.

30. McLaughlin, P.J. \& Zagon, I.S. Modulation of human neuroblastoma transplanted into nude mice by endogenous opioid systems. Life Sci 1987, 41: 1465-1472.

31. Burrows, F.J., Haskard, D.O., Hart, I.R. et al. Influence of tumour-derived interleukin-1 on melanoma-endothelial cell interaction in vitro. Cancer Res 1991, 51: 4768-4777. 